Itinéraires Itinéraires

Littérature, textes, cultures

\title{
Yann Potin (dir.), Françoise Dolto. Archives de l'intime
}

\section{Véronique Montémont}

\section{OpenEdition}

\section{Journals}

Édition électronique

URL : http://journals.openedition.org/itineraires/1326

DOI : 10.4000/itineraires.1326

ISSN : 2427-920X

Éditeur

Pléiade

\section{Édition imprimée}

Date de publication : 1 décembre 2009

Pagination : 194-195

ISBN : 978-2-296-10791-5

ISSN : 2100-1340

Référence électronique

Véronique Montémont, «Yann Potin (dir.), Françoise Dolto. Archives de l'intime », Itinéraires [En ligne], 2009-4 | 2009, mis en ligne le 03 septembre 2014, consulté le 22 septembre 2020. URL : http:// journals.openedition.org/itineraires/1326 ; DOI : https://doi.org/10.4000/itineraires.1326

Ce document a été généré automatiquement le 22 septembre 2020.

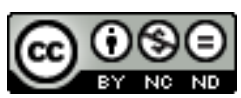

Itinéraires est mis à disposition selon les termes de la licence Creative Commons Attribution - Pas d'Utilisation Commerciale - Pas de Modification 4.0 International. 


\title{
Yann Potin (dir.), Françoise Dolto. Archives de l'intime
}

\author{
Véronique Montémont
}

\section{RÉFÉRENCE}

Yann Potin (dir.), Françoise Dolto. Archives de l'intime, Paris, Gallimard, 2008, 251 pages, ISBN : 978-2-070-12369-8

1 Il existe déjà un certain nombre de documents levant le voile sur ce que furent la vie privée et l'enfance de Françoise Dolto. La psychanalyste elle-même a sacrifié au rituel de l'autobiographie avec Enfances (Seuil, 1986), puis a livré, juste avant de mourir, deux longs entretiens où elle revenait sur l'ensemble de sa vie, et qui, transcrits par Alain et Colette Manier, ont été publiés au Seuil en 1988 sous le titre d'Autoportrait d'une psychanalyste. L'entreprise biographique s'est enrichie en 1991, puis en 2005, de la publication de la correspondance de Dolto, là encore d'une grande richesse, puisqu'on y voit s'esquisser, de façon croisée, la destinée de la femme et celle du médecin pionnier qu'elle fut. Ces publications sont aujourd'hui complétées par un album original, intitulé Archives de l'intime, et réalisé en 2008 à l'occasion du centenaire de la naissance de la célèbre thérapeute.

2 Il n'était pas facile, compte tenu de l'immense popularité de Françoise Dolto, des nombreux documents (publications, enregistrements, émissions) et travaux qui lui ont été consacrés, d'ajouter une pièce inédite au dossier biographique. Pas facile non plus d'éviter l'hagiographie et les images qui font maintenant partie de la culture populaire, celles de la vieille dame à lunettes débonnaire et médiatique. Archives de l'intime, paru sous la direction de Yann Potin, et coécrit par Catherine Dolto (fille et ayant droit de Françoise), Muriel Djéribi Valentin, Manon Pignot et Jean-Pierre Winter, esquive tous ces pièges et, qui plus est, sait surprendre.

3 La photographie de couverture, un photomontage chamarré qui juxtapose objets, dossiers, photos et lettres, donne la note de ce que sera le volume: un recueil 
d'archives justement, dans toute leur richesse et leur disparate. On peut suivre, de chapitre en chapitre, en feuilletant les albums familiaux, la destinée de Françoise Marette, jeune fille intelligente et mal à l'aise dans son corps trop lourd, puis étudiante, médecin, amoureuse, mère de famille, praticienne, femme de radio, écrivain. Les auteurs ont fait le choix de ne tendre à aucune exhaustivité, mais de montrer la plus grande diversité possible de documents: photographies et fac-similés abondent, montrant photos de famille, dessins, lettres enfantines, rédactions scolaires, diplômes, cartes d'alimentation, blocs d'ordonnances, livres annotés, carnets de dépenses, correspondances, dessins, polaroïds, photos de lieux symboliques, agendas, brouillons, etc. En effet, Françoise Dolto fut une remarquable archiviste d'elle-même (Yann Potin parle d'une "archivie»). Issue d'une famille où les mères préparaient pour chaque enfant des albums comportant les portraits de toute la généalogie, elle a perpétué ce geste en conservant toutes sortes de documents, puis en réalisant à son tour pour ses deux fils et sa fille des albums rétrospectifs.

Ce qui se dit à travers cette collection, là aussi, révèle quelques surprises. Derrière la femme rassurante et la thérapeute s'est cachée une jeune fille remplie de doutes, qui a dû mener une lutte âpre pour poursuivre ses études. Après des expériences sentimentales malheureuses, la rencontre en 1941 avec Boris Dolto, médecin russe orthodoxe, est synonyme d'amour fou, ce dont témoignent les images du couple étreint, les lettres d'une tendresse inconditionnelle; ce que révèle aussi, de manière plus inattendue, un très beau dessin érotique griffonné sur du papier à en-tête. Quant à la croissance des enfants, elle a fait l'objet, en plus de l'iconographie des albums, d'une sorte de documentation écrite, où le regard de la mère est aussi celui d'une clinicienne passionnée.

Cet ensemble documentaire à l'hétérogénéité heureuse est livré par prélèvement, petites touches, morceaux, dans une logique qui est à la fois celle de l'anthologie et du kaléidoscope. Il ne s'agit pas tant de révéler le contenu des documents, que de montrer la puissance du geste de collection, les nombreuses sources qui forment un intime. Tous les manuscrits sont accompagnés de transcriptions, les photos sont assorties de légendes, le tout est éclairé de textes brefs et pertinents, qui ne prennent jamais le pas sur l'archive elle-même. On soulignera la qualité de la réalisation qui a su mettre en valeur (notamment par un traitement chromatique superbe) les pièces exposées dans la page, composant harmonieusement les équilibres entre photographies et pièces manuscrites, sources autographes et commentaires. Parcours biographique, invitation au butinage, reflet foisonnant et vivant, Archives de l'intime nous offre un nouveau visage de Françoise Dolto : celui d'une héritière de son histoire familiale, d'une femme dont la passion des autres n'excluait pas l'introspection et l'intériorité, et surtout d'une passeuse d'images et de mémoires. 


\section{AUTEURS}

\section{VÉRONIQUE MONTÉMONT}

Université Henri Poincaré de Nancy, ATILF - IUF 